\title{
Sponsorship of College Activities
}

\section{Guidelines}

(1) Sponsorship should be used to improve the quality of scientific activites and should not be used for hospitality and social events. Sponsorship might be used for speakers' expenses, hiring of premises, printing and circulating programmes, provision of visual aids etc.

(2) Approaches to or from potential sponsors, whether they be pharmaceutical companies or other commercial organisations, should be negotiated only by Officers of the College or the Secretary acting on their behalf. This includes Officers of Divisions, Sections, Standing and Special Committees.

(3) All financial transactions should be handled by the Finance Department. This will ensure that Sections and Divisions receive the benefits of the College's charitable status. The Finance Department will produce detailed accounts of any meeting on request.

(4) Appropriate acknowledgement of the source of sponsorship may appear on the notice of any meeting so sponsored.

(5) Acceptance of sponsorship by the College should never be represented by the sponsor as an endorsement of its products.
(6) When meetings are held in hospitals all arrangements, including the choice of speakers, should remain under the control of the doctor organising the meeting.

(7) When a commercial company organises its own meeting and invites speakers, subsidises participants' expenses or provides hospitality, the College's name must not be used or acknowledged. It is acceptable for speakers who are office-holders to be described as such at educational meetings.

(8) Every effort should be made to select suitable titles for named lectures. The use of the name of a commercial organisation should be avoided if at all possible.

(9) The help of industry and, in particular, the pharmaceutical industry in supporting medical education activities is understood and appreciated. The overriding consideration where the College is concerned is that the choice of the scientific programme and the level of hospitality and advertising should be controlled by College officials.

\section{Prizes, Medals and Travelling Fellowships of the Royal College of Psychiatrists}

\section{Gaskell Medal and Prize}

This Prize was instituted in 1886 and is named after Samuel Gaskell, Medical Superintendent of the County Asylum, Lancaster, after whom Gaskell House in Manchester is also named.

The Prize was established from a Trust Fund in memory of Dr Gaskell, but it is now supported almost entirely from College funds. It has increased in value over the years and now stands at $£ 500$ although the medal, originally gold, is now silvergilt. Many of its holders have achieved distinction in psychiatry.

The Prize has always been considered one of the foremost academic distinctions in clinical psychiatry and members are asked to bring it to the notice of suitable candidates at their hospitals who may be eligible to compete.
Entry forms may be obtained on application to the Dean and should be completed and returned by 31 March 1991. An entry fee of $£ 30.00$ is charged, returnable to bona fide candidates. The annual examination for the Prize is held in May or June and includes a written paper, a clinical and an oral.

\section{Regulations}

Candidates must (a) have been qualified medical officers in one or more mental hospitals or clinics in psychiatry in the United Kingdom or elsewhere in the British Commonwealth for at least two years; (b) have passed the MRCPsych Examination or an equivalent qualification within the last four years. 